\title{
THE PERSONA IN AUTOBIOGRAPHICAL GAME-MAKING AS A PLAYFUL PERFORMANCE OF THE SELF
}

\author{
STEFAN WERNING
}

\begin{abstract}
The paper at hand investigates forms and interpretations of author personae in autobiographical videogames. While, previously, autobiographical modes of expression have only been discussed in a few game-based artworks (Poremba 2007), the availability of free, easy-to-use tools like Twine and Ren'Py gradually affords autobiographical writing as a cultural technique outside of deliberately artistic endeavors. Therefore, the paper considers the creation and distribution of autobiographical games as a playful form of identity politics. For that purpose, a comparative content analysis (cf. e.g. Rössler 2012) of selected autobiographical games will be conducted, taking into account rhetorical and audiovisual elements but focusing on procedural design strategies and "bias" (Bogost 2008, 128). The corpus includes explicitly autobiographical sketches like Gravitation (2008) and Dys4ia (2012), but also cases in which the autobiographical characteristics are only implied like The Average Everyday Adventures of Samantha Browne (2016) as well as less polished, sometimes unfinished vignettes.
\end{abstract}

This approach will be selectively complemented by a rhetorical analysis of paratextual elements such as developer statements and user comments. Play and games are increasingly recognized as modes of conceptualizing and expressing individual identity (Frissen et al. 2015, 35-36) that are particularly compatible with postmodern sensibilities. Consequently, the focus of the analysis will lie on how the implementation of the author personae as playable characters enable the developers to curate their identity online, both in terms of Moreno's psychodrama (Moreno 1987) and Foucault's technologies of the self (Aycock 1995).

\section{KEY WORDS}

Autobiographical Games, Procedural Rhetoric, Amateur Game-Making

\section{INTRODUCTION AND DEFINITIONS}

The goal of this article is to investigate forms and uses of author personas in autobiographical videogames. Previously, autobiographical modes of expression in digital games have been discussed in academic publications primarily with reference to the overall expansion of game-specific storytelling techniques (Haggis 2016) as well as to game-based artworks, particularly [domestic] and [rootings] by US game designer/scholar Mary Flanagan (Poremba 2007). This analysis addresses important issues such as the construction of the artist's subjectivity (Poremba 2007) within the playable art piece and the related notion of agency. However, while [domestic] employs autobiographical references as a deliberate artistic 
strategy, the article at hand will focus on the persona in autobiographical games from a comparative perspective, that is, as a) an emergent 'genre' within independent game production over the past ten years - including mostly small-scale games from Jason Rohrer's Passage (2007) to Andrea Ayres Deets' The Average Everyday Adventures of Samantha Browne (2016) - and as b) a form of playful identity performance.

Building on Paul Ricœur's notion of narrative identity, Frissen et al. (2015) argue that play is becoming an increasingly relevant metaphor of identity politics in "postmodern culture" (Frissen et al. 2015, p. 9-10). The authors criticise Ricœur for his almost exclusive focus on the novel as a 'reference medium' for identity construction (Frissen et al. 2015) and argue that the pervasiveness of games in contemporary culture make it more plausible for people to envision their identity in terms of play rather than narrative. For Ricœur narrative identity begins with the "narrative prefiguration of our daily life" (Frissen et al. 2015, p. 32), the first of three steps he terms mimesis1, 2 and 3. Analogously, Frissen et al. posit a "ludic prefiguration of our everyday life", that is, thinking of our "lived experience" as playful and "the expression of this experienced ludic nexus in more or less explicitly articulated and regulated games" (2015, p. 35). The authors do not systematically exemplify their theory, pointing mostly to various playfully competitive forms of smartphone use, including case modification and the importance of "lucky telephone numbers" (Frissen et al. 2015, p. 37) in Indonesia for illustration. The article departs from this theoretical vantage point and aims to provide a case study of how playful identity construction manifests itself by considering autobiographical games and the representation of their developer personas in playable form. In particular, it aims to show how in-game personas are constructed primarily as constellations of game rules rather than audiovisual or narrative tropes, and that these personas become part of the identity politics of their creator within the online communities where they are shared. As the argument at hand foregrounds autobiographical game-making, including small-scale, less developed vignettes that do not lend themselves to 'close reading,' a comparative content analysis (for example Rössler 2012) of the games and prototypes will be conducted, selectively complemented by para-textual elements such as developer statements or user comments.

\section{The Persona in Artistic and Personal Works}

The notion of persona has been defined differently in various disciplines such as literary studies and sociology but also in domains such as user experience design (Idoughi et al. 2012) and advertising (Dion \& Arnould 2016), which are more directly aimed at operationalisability. It has even been applied to non-human entities as in St. John's (2014) study of persona curation in corporations such as Mobil Oil. This makes it all the more important to start by choosing definitions that fit the goal of this argument, conceptualising the complex relationship between in-game characters and authorial 'voices' in autobiographical games and the use of the games as 'props' in performing their creators' public personas. For that purpose, a useful basic distinction is the one between ethos and persona (Cherry 2007) in written discourse. The former, drawing on Aristotle's Rhetoric, refers to a speaker's need to "portray themselves [...] as having a good moral character" as well as "practical wisdom" (Cherry 2007, p. 386) in order to be persuasive. The latter, which refers to literary rather than rhetorical contexts, has been more controversially debated as a "critical tool" (Cherry 2007, p. 391) to understand the relationship between author and narrative voice. As it is not possible to reflect the complexity of this discussion and its connection to the equally contested notion of "authorial presence" (Cherry 2007, p. 392), the article at hand will focus on the mechanics of framing the persona-author relationship, that is, on textual strategies in autobiographical games in which the distinction between persona and ethos can be blurred (Cherry 2007, p. 395). 
The notion of persona has also been mobilised in research on autobiographical writing, particularly in the early to mid-1990s. For instance, Olshen argues that personal identity under postmodern conditions had become a "problem of textuality" $(1995$, p. 5), that established forms of 'writing the self' were not congruent with postmodern concepts of the self any longer. Similarly, James Olney's Metaphors of Self, and John Morris's Versions of the Self emphasise the persona as a construction rather than a reflection of the author as a person. Despite its age, the text makes a particularly relevant point that can be fruitfully adapted to video game autobiographies. The notion of persona helps overcome the "reality-appearance dichotomy" (Barros 1992, p. 6); just as, on stage, the "mask is the reality," (p.6) in autobiographical writing, the respective 'version of self' is a "metaphor for the inscribed self of the text" (p.6) rather than a guise.

This argument resonates well with the notion of playful identities or, more generally, the "double experience" of play (Frissen et al. 2013, p.18). Rather than upholding the ontological distinction between play and reality that characterised Johan Huizinga's early definition, Frissen et al. follow Eugen Fink's argument that play takes place simultaneously in the real world and the imaginary world of the game. They thereby draw on but also challenge Johan Huizinga's original definition of play as "distinct from 'ordinary' life" (1949, p. 9), that is, as an activity that is both without 'real-world' consequences and spatio-temporally separated from the sphere of those not playing. This 'updated' definition of play, which the authors label "Homo Ludens 2.0" (Frissen et al. 2013, p.10) is more applicable to the playful self-expression of game-makers through their playable personas.

\section{(Autobiographical) Game-making as cultural practice}

The aforementioned popularity of the persona concept in postmodernist readings of autobiographies can be attributed to a multiplicity of new media paradigms at the time, including early prototypical virtual reality applications (Rheingold 1991), text-based online environments, and the shift towards 3D in video games. In contrast, the construction of personas in autobiographical game-making is related to the standardisation of existing technologies and the availability of free, easy-to-use tools like Twine (2017) and Ren'Py (2017). These tools have, over time, made autobiographical game-making feasible as a cultural technique or a 'technology of the self' in a Foucaultian sense outside of deliberately artistic endeavors. As digital games are still often framed in mainstream media discourse as highly complex, multi-million dollar entertainment productsi, it might appear counterintuitive to think of game-making as an intimate, personal activity. However, Thompson (2002) already reported on how games developed using Adobe Flash became an increasingly common form of "social comment" on the events of 9-11 and the subsequent US invasion of Iraq. Roth (2015) also investigates amateur game creation particularly in Japan, for example in the form of dojjinshi visual novels displayed twice per year in fairly ritualised form at Comiket (2015, p. 184), and Werning (2017) illustrates how game-making as a form of self-expression relates to contemporary notions of citizenship and participation. Still, contemplating one's persona as a videogame protagonist is still visibly new territory, even for established designers such as Steve Meretzky and Erin Robinson, who participated in the GDC 09 design challenge to conceptualise an autobiographical game on the topic of "my first time" (Gamespot Staff 2009).

The first part of this article investigates textual strategies of constructing the persona in autobiographical games. Using a comparative perspective and a fairly large corpus, the goal will be to identify generalisable patterns of representation. The second part of this article goes beyond a formal analysis of the games themselves and discusses Moreno's psychodrama and 
Foucault's technologies of the self as theoretical frames to analyse autobiographical gamemaking as a form of identity politics.

\section{THE PERSONA IN AUTOBIOGRAPHICAL GAMES}

\section{Outlining autobiographical games as a genre}

While a more comprehensive investigation of autobiographical games as a genre is beyond the scope of this article, it is useful to briefly demarcate the corpus. Describing autobiographical writing as a coherent genre has long been problematised in autobiography studies. For example, Loesberg argues that the genre qualities of autobiography are defined by "extra-textual" concepts such as "intention" or "authorial sincerity" (1981, p. 169) rather than more tangible formal characteristics. Similarly, autobiographical games can retell part of the creator's life story or be rather loosely based on individual idiosyncratic experiences or thoughts. Some are text-based and take the form of a conversation while others allow for controlling the creator persona directly. Since the goal of the article is not to map out the field but to provide a theoretical framework for this rather novel creative practice, it is more productive to conceive of genre as a cognitive category (Olson et al. 1981), that is, to focus on how users interpret a game and its protagonist based on their knowledge about its (explicit or implicit) autobiographical status.

For instance, one of the most actively discussed autobiographical games of all time is That Dragon, Cancer (Ryan and Amy Green, 2016), which is based on the designers' experience with their son Joel, who was diagnosed with cancer at the age of twelve months and died only a few years later. Even though the game is formally less interesting and novel than it is often given credit for, the particularly tragic real-world events it conveys encourage most players to adopt a very different disposition than the one with which they would normally approach a digital gameii.

As this article focuses on game-making as cultural practice, it does not address the few commercially produced autobiographical games but rather includes smaller autobiographical sketches like Gravitation (2008) and Dys4ia (2012), and cases in which fictional personas are deliberately used as 'theatrical masks' to implicitly convey autobiographical content as in The Average Everyday Adventures of Samantha Browne (2016) iii. Writing for The Telegraph, Nina White (2016) even speaks of a "new wave of biographical video games". Thus, rather than analysing one or more individual games, the following sections will propose several interrelated analytical categories and illustrate how to use them with reference to a broad range of examples.

\section{Constructing a persona through procedural rhetoric}

Corresponding to the different definitions of the persona concept across disciplines, several methodological approaches have been proposed to operationalise persona studies research, ranging from literary criticism (Stern 1993) to psychological perspectives such as Interpretive Phenomenological Analysis (IPA) or network analysis and data visualisation (Marshall et al. 2015).

As digital games are still a comparatively young medium, existing approaches to analyse the 'messages' and biases that they convey are still heavily disputed. Ian Bogost (2009) points to several competing ontologies that underlie contemporary game scholarship, such as the basic distinction whether games should be regarded primarily as narratives with distinct formal and stylistic properties, as rule systems or as 'experiences' that people have, which may be more or 
less directly shaped by game rules. For the purpose of this argument, the notion of procedural rhetoric (e.g. Bogost 2008), which focuses on the interplay of narrative and gameplay elements to analyse how games produce meaning by shaping the player's interactional affordances, will be used to make sense of how personas are implemented in autobiographical games. Bogost envisions playing the game as a form of (Socratic) dialogue, that is, a persuasive communicative situation, which - among other things - is defined by categories such as "elegance, clarity, and creativity in communication" (2008, p. 124). However, rather than defining the term 'procedure' in a way that would make it readily operationalisable, he focuses more on 'procedurality' as a "core practice of software authorship" (Bogost 2008, p. 122). To make this more applicable for "proceduralist readings", Treanor \& Mateas (2011) propose to understand meaning-making in games through the interplay of dynamics (i.e. game rules), aesthetics, and theme (i.e.

audiovisual elements). The authors point out the semanticisation of simple actions like walking and avoiding in games (Treanor \& Mateas 2011, p. 5) and addresses important aspects such as the consistency of different rules, that is, procedural representations, within one game (Treanor \& Mateas 2011, p. 7). This perspective allows for interpreting how the games frame the personas of their creators, for example, by selecting the actions the playable characters can and cannot perform. For instance, while games usually seek to empower the player and provide meaningful choices (according to acclaimed game designer Sid Meier), the scenarios in That Dragon Cancer only allow for metaphorical interactions that have no impact on the outcome of the underlying narrative.

Applying this to autobiographical games, one recurring procedure involves representing the passing of time as the in-game persona traversing an allegorical space. While earlier media forms facilitate adapting a person's life in narrative terms, games characteristically adapt source material by turning it into "spatial stories," in which "plot is transformed into geography" (Wallin 2007, para. 4). A prime example of this is Jason Rohrer's Passage (2007), which - rather than recounting autobiographical episodes - succinctly summarises the author's view on the transitoriness of life using the basic genre conventions of a maze game. However, despite the outward appearance of the game environment as a maze (supported by different visual themes that are determined randomly upon starting the game), the dynamics (according to Treanor/Mateas) of the maze have been hollowed out. There are no goals or exits and no distinct alternating paths; even partial progress does not seem to matter as the game keeps a score but there is no persistent list or even a single 'high score'; instead, the performance indicator simply disappears after the play session is over.

Stylising the environment as a maze without a purpose frames the author persona (which remains fairly nondescript in Passage) in an interesting way. If the player chooses to take a partner - Rohrer (2007) has noted this character represents his spouse - at the beginning of the game, that character walks alongside the protagonist, which can make it impossible to navigate narrow 'passages'. According to the game's algorithmic procedures (including movement, collision detection etc.), the author persona and his partner are framed as a unit, constituting one playable character. The maze is a popular spatial concept that has been interpreted differently over time. For instance, the quasi-autobiographical A Closed World (2013), developed at the MIT Game Lab, uses a forest maze as a metaphor for the sometimes treacherous social environment that queer people have to navigate striving for social acceptance of their sexual identity. In this case, the notion of a 'playful prefiguration' proposed by Frissen et al. (2015) is particularly compelling, as the designers deliberately use allusions to iconic game franchises like The Legend of Zelda (which usually portray a more innocuous search for adventure) to frame their lived past experience. 
Rather than portraying the author personas as character archetypes with a distinct outward appearance, most games implement them as a set of characteristic actions or action possibilities. For instance, Depression Quest (Zoe Quinn, 2013) does not explicitly characterise its protagonist but uses it as a projection space for the player's own assumptions as well as designer Zoe Quinn's and writer Patrick Lindsey's personal experiences with depression. The game is text-based and players select 'their' preferred reaction to in-game situations using multiple-choice menus. To represents the protagonist's fragile mental state, the game often characteristically displays but disables the 'best' courses of action, thereby marking the protagonist's awareness of what the 'right' choice is, but also their inability to make it as a central tragic moment. While the uniformity of the input scheme emphasises the idiosyncratic phrasing of the 'choices' in Depression Quest, the game Memoir en Code (Alex Camilleri, 2015) takes a different route by framing the author's persona, a game development student moving between Italy, the Netherlands, the UK, and Sweden, as a collage of very short, seemingly incoherent playable vignettes. All of these vignettes are modeled after interface tropes from various game genres; while this might seem distracting, game interfaces have less "obligation to fictional coherence" (Jørgensen 2013, p. 4) but are "self-referential" (Jørgensen 2013, p. 9), that is, they "bring[...] attention to the mediation process" by addressing both the game world and the player. As such, the hypermediacy itself appears to create a sense of identity and continuity across the different activities. For instance, by pressing the button at the right time, the player can select one from several responses at a Dutch supermarket counter, where the idiomatic Dutch statement is the hardest to 'hit' (thresholds for all the responses are marked through colour coding as in a music rhythm game). Moreover, the game uses the music album as a framing metaphor and, in the words of its creator, is even "designed to be being experienced similarly to a music album" (Memoir En Code: Reissue 2017). This metaphor implies a deliberately ambivalent, loose thematic, but also formal overlap between different game scenes, similar to 'tracks' on a record. As users commonly develop a close "relationship between [their music] records and [their] sense of self" (Shankar 2000, p. 29), the use of this reference medium intensifies the perceived coherence of Alex Camilleri's in-game persona as a 'representation of self' in the form of a collage of idiosyncratic actions (e.g. greeting someone with a handshake, finding a quiet place to study or throwing rocks into the ocean). As with tracks on a music album, the game suggests an order to these constitutive actions/scenes but they can be (re)played in any given sequence.

This example also demonstrates that, in some aspects, in-game personas clearly differ from those in autobiographical literature. For example, Barros argues that the autobiographical persona usually undergoes a distinct change while still maintaining basic continuities; this mode of transformation is described by a specific rhetorical mode, "figura" (1992, p. 7-8). In contrast, in-game events are necessarily iterated over multiple play-throughs. Thus, instead of marking a development between two states, autobiographical games present personas as conglomerates of interrelated procedures, which in the act of play manifest themselves as multiplicity of slightly varying outcomes.

\section{The interface as bridge between player and persona}

In the "creator's statement" for his game Gravitation (2008), Jason Rohrer argues that he cannot imagine "any other rendition of [him]self for an autobiographical game" than pixel art (2008). This quote illustrates that, compared to text-based autobiographical media, games can pose an epistemic problem regarding the indexical relationship between author and character as their designers have to choose a 'resolution', that is, a granularity of representing their ingame re-creation. In autobiographical literature, authors can create an epistemic connection with their texts by repurposing earlier texts or verbatim quotes and the culturally constructed 
'authenticity' of autobiographical 'mobile filmmaking' (e.g. Schleser 2014) relies on being able to 'capture' rather than having to re-create the likeness of the videographer. Apart from using a distinctly abstract and multivalent art style such as pixel art (That Dragon, Cancer transfers that approach to 3D environments with its sparse, almost untextured scenes). A common strategy to avoid this lack of indexicality is using standardised tools and graphical assets to establish a seemingly 'neutral' vantage point. Other techniques to evoke indexicality often revolve around the aforementioned principle of 'spatial stories'. For instance, Will O'Neill establishes a connection between himself and his in-game persona Evan Winters by deliberately modeling the protagonist's apartment in Actual Sunlight (2015) after his own at the time of creating the game (Smith 2015).

However, the most important 'bridge' between author, characters, and playeriv, which frames the identification with the author persona, is often the interface. While this can differ radically between games, one commonly used technique is the text-based interaction logic of games created using Twine, a popular tool for autobiographical game-making (Ellison 2013a). The scene is presented as a continuous text with HTML-compatible formatting options such as bold type or lists, and any word or phrase can be marked as a hyperlink that players can click to advance through the story. For example, the game Sacrilege by Cara Ellison (2013b), which lets players re-enact the author's 'quest' for a one-night stand in a club, characteristically plays with this scheme for various effects. For instance, the author's in-game representation (which addresses the player as 'you') breaks down a sentence comprising her perception of one potential partner into multiple chunks and the player has to click on each one in order to 'effectuate' them: "Matthew is tall ... dishevelled ... he makes you laugh". This simple technique captures the wandering of the protagonist's gaze and can be interpreted as a remediated "performative utterance" (cf. e.g. Tronstad 2015, p. 60). Originally, the term refers to a speech act that does not describe but perform an action, and thus can only be judged as succesful or unsuccessful rather than as true or false. Similarly, clicking on the words constitutes an in-game utterance that 'brings into reality what it signifies' by allowing the player to symbolically recreate the author persona's step-by-step perception of Matthew. The fact that the sentence parts appear below each other and visually form a complete sentence supports this interpretation. The same technique is repeated moments later (as well as throughout the game) through the sentence "You grab Matthew's shoulder and yell his name ecstatically:

MATTHEWWWWWWWWW", where the name needs to be clicked to 'perform' the described action and intensify the perceived subjectivity of the in-game character (Ellison 2013b). A different technique is the use of repetition; for instance, as the protagonist initiates contact with 'Matthew,' the sentence "he is going to kiss you" is repeated and needs to be clicked several times to advance. This creates a sense of immediacy and direct, 'unfiltered' insight into the protagonist's mind. Depending on the pace and consistency of clicking, it may even be interpreted to signify her heartbeat, breathing or other internal rhythm. The notion of immediacy is further supported by formal elements, such as the lack of interpunction in certain parts of the text. Elsewhere, clickable text segments are action verbs such as "investigate" or "engage interpretation," which harkens back to the interface conventions of more traditional text-graphic adventures.

Other games show how simple point-and-click interaction can be modified by going beyond purely textual means. For instance, Nicky Case's Coming Out Simulator (2014) usually sticks to the 'formula' by giving the player dialogue choices via multiple-choice buttons. However, after having established this convention over some time, the game introduces subtle changes. When Nicky's mother expresses bias towards his gay friend, the game only offers the word "what" as a response, yet in three degrees of intensity. It thereby frames this reaction as particularly immediate (as it is without alternative), but leaves it to the player to 'perform' its 
nuances, thereby making the utterance feel much more like their own. The game adds other formal elements that enhance the 'performative' feeling of clicking on textual phrases to move the dialogue along. For instance, it uses two different sounds when the protagonist or the interlocutor make a new utterance. As the dialogue speed is determined by the length of the sentence, this creates an audible 'rhythm' for the in-game conversations. Moreover, previous phrases float upwards until they leave the screen rather than simply disappearing, which provides some context to the reading experience, creating the impression that one statement flows from the preceding one rather than appearing out of thin air. While this form of text-based input is one of the simplest conceivable interaction paradigms, the two game examples above indicate the vast spectrum of potential procedural bias it affords and might serve as a blueprint for investigating the connection between interaction and in-game personas in more complex cases.

\section{Persuasive aspects of autobiographical games}

While not applicable to the 'genre' as a whole, many autobiographical games stage the creator's persona as a prototype of a particular trait they embody. For example, Anna Anthropy based the game Dys4ia (2012) on her own experience with hormone replacement therapy, not just to demonstrate her personal sensibilities during that phase, but also to critique the everyday forms of behaviour that, deliberately or not, ostracise transgender people in general. Accordingly, it appears plausible to conceive of playable autobiographies in terms of rhetorical persuasion (Virtanen \& Halmari 2005, p. 20), characterised by a specific use of ethos, pathos, and logos (Virtanen \& Halmari 2005, p. 5). As the author draws on their lived experience, the aspect of ethos or, more specifically, the "'good character' of the persuader" (Virtanen \& Halmari 2005 , p. 6), naturally plays a prominent role. Traditionally, this requires demonstrating the moral grounding of the 'speaker,' making them appear trustworthy and their behaviour appear congruent with their message. Yet, examples like Robert Yang's micro games Hurt Me Plenty (2014) or Rinse and Repeat (2015)v, where each express one aspect of homosexual sensuality based loosely on the creator's personal experience, suggest a different emphasis. As the player has agency in 'shaping' the creator's persona through their in-game behaviour, ethos here primarily operates by establishing an empathetic relationship, in which the competence and moral compass of the 'speaker' are de-emphasised or, rather, shared between author and player. Similarly, the narrative in Depression Quest contains numerous references to idiosyncratic observations that readers/players might be familiar with from own experience, for example the "habit of waking up 10 - 20 minutes before your alarm rings". Some of these also appear in the multiple-choice options, which usually don't just describe the action but add connotations from the persona's perspective. The goal of these procedures is not to communicate information, but to produce a phatic communion (Miller 2008), that is, to perform a sense of connectedness by referring to common, shared sentiments.

\section{Developing procedural literacy in the process of identity performance}

To conclude this first part, it is important to note that many autobiographical games are still very light on procedures; even though they supposedly allow the player to shape or even cocreate the author personas, this interaction is still limited in practice. For instance, The Average Everyday Adventures of Samantha Browne employs several interesting narrative strategies such as giving the player a glimpse into the character's online identity on a fictitious online social network but limits the interaction to selecting multiple-choice options (e.g. how many packets of oatmeal to make). All choices add to a stress meter which aptly communicates that for a person with social anxiety there often is no ideal choice in everyday situations. However, the seemingly arbitrary amount of anxiety increase, which doesn't afford the player to form 
cognitive patterns, does not support this 'tragic' connotation but rather frames the persona's actions, and the player input they depend on, as arbitrary. A cursory look at gameplay videos (for an example, see The Average Everyday Adventure 2016) of the game provides some anecdotal evidence that players connect with the tone of writing, the seemingly hand-drawn art style, and particular narrative motifs (e.g. the lack of clarity as to who can use which appliances in a public dorm kitchen). However, the choices and consequences are usually commented on in a tongue-in-cheek manner, which suggest limited personal engagement.

In other cases, the game itself is used as a metaphor to characterise the protagonist persona and focuses on audiovisual characteristics rather than procedural rhetoric. For instance, Nina Freeman's (2014a) Space Dad presents a wildly imaginative interpretation of a young girl coping with the fact that her father is rarely home because of his work as a truck driver. The game employs very simple mechanics inspired by early arcade games in combination with informants such as pixel art style, 1980s iconography, and chiptunes, thereby positing the medium of video games itself as a 'filter' through which the persona of the authoras-child interprets the world. Freeman also uses the child persona, exploring an early memory of herself contemplating sexuality, in another autobiographical vignette called how do you Do It? (Freeman 2014b).

By investigating strategies of "textual poaching" (Pelletier et al. 2010, p. 90) in amateur game design, Pelletier et al. (2010) argue that game-making is becoming a form of identity work. The authors reference Henry Jenkins's notion of textual poaching and the corresponding impetus to achieve a form of mastery, but transfer these concepts from media consumption to production practices. They study the amateur creators' repeated use of motifs and assets from the Star Wars franchise as a "framing device" (Pelletier et al. 2010, p. 101), which also suggests that playfully achieving some form of mastery and forming "social bonds" (Pelletier et al. 2010, p. 96) with others in the process becomes an important part of their 'creator' identity. Similarly, the collective acquisition of procedural literacy over time can be regarded as an important aspect of autobiographical game-making as a form of identity performance.

\section{IN-GAME PERSONAS AS TOOLS OF PLAYFUL IDENTITY POLITICS}

The scope of this article does not afford an in-depth analysis of how game makers, ranging from self-taught amateurs to industry professionals, utilise their autobiographical games to position themselves in their online social circles. Yet, this second, shorter section is intended to provide some theoretical vantage points for that purpose as well as anecdotal evidence indicating why such analysis would be relevant.

\section{Game-making as psychodrama and the autobiographical game as prop}

In a presentation at the tech conference Codemotion, Alex Camilleri describes game-making and his game, Memoir en Code, in particular as his "psychologist" (2016). For Camilleri, the highly systematic act of scripting a game and the need to rethink his own memories through the lens of gameplay mechanics (and, more specifically, mechanics that are feasible to implement with limited programming skills) proved to be useful in selecting and organising relevant occurrences and understanding their specific impact on his psyche. This anecdote suggest that Julio L. Moreno's concept of psychodrama (1987), originally a psychiatric technique that involves acting out psychologically demanding situations in a theatrical context, can be a very useful starting point to conceptual the social functions of in-game personas.

Traditionally, psychodrama requires five instruments, starting with a subject (or actor) and a stage, a flexible space where "reality and fantasy are not in conflict" (Moreno 1987, p. 14), 
and which affords spontaneity (i.e. freedom of expression) and the "enactment" (Moreno 1987, p. 14) of a psychological conflict. The remaining three instruments are the director, acting as "producer, counselor and analyst" (Moreno 1987, p. 15), therapeutic aides or auxiliary egos, which assist both the director and the subject, and an audience. Moreno posits a reciprocal relationship between audience and subject, as the former usually needs to provide acceptance and support but can also be "helped by the subject" (Moreno 1987, p. 15), in which case the roles are reversed. In the case of autobiographical game-making, this face-to-face situation on a stage is being remediated and while all these 'instruments' are present, some appear in altered form. As the game-makers present a respective game as 'their story' online (e.g. on their website or a distribution platform such as Steam), the audience partly takes over the role of the director, particularly as counselor and - to a lesser degree - as analyst. In turn, the digital authoring tool (e.g. Twine or RPG Maker) acts as director and producer, both constraining the re-telling of the self in characteristic ways and ensuring that it is communicated in such a way that the audience can provide meaningful input. Furthermore, using these tools, the subjects can take over the role of the auxiliary egos themselves by writing different characters as mirrors of the protagonist persona's self-presentation such as the non-playable characters (NPCs). The parameters of how they frame the performance can be easily modified just as supplementary actors can quickly adjust their behavior as needed. Yet, the social context evidently is very different if the subject herself is 'controlling' the auxiliary egos through code, thereby taking over multiple perspectives on the production of the psychodrama.

Moreno uses theatrical metaphors from a psychoanalytical vantage point; accordingly, he draws on the Jungian definition of the persona as a role 'played' in public-a mask or shield-and encourages the subject to actively experiment with different personas in a controlled environment. This use of theatre as metaphor is comparable to Goffman's sociological view on face-to-face interaction as a concurrent performance of different roles or parts (Goffman 1956), which also includes the theatrical persona (Goffman 1956, p. 10) as reference point. Following up on that metaphor, it appears plausible to interpret the autobiographical games as props used in the performance of the self, as a partially externalised form of the role the author is playing. As Marshall et al. (2015) demonstrate, the curation of a game "developer persona" in the "creative and cultural industries" occurs through processes of bricolage and the "presentation, aggregation, remediation and recirculation of digital objects". The authors illustrate this hypothesis by referring to Markus 'Notch' Persson, the designer of the iconic game Minecraft, who expresses different sides of his developer persona by participation in non-profit game jams or being active on Twitter. Autobiographical games of established developers perform similar functions but are very particular 'digital objects' because they comprise more or less direct representations of the author persona. These representations are constantly offset against both other textual characteristics of the games or other forms of self-presentation such as interviews and social media activity. For instance, in the game Papo y Yo (2012), the Columbian designer Vander Caballero reportedly reflects on his childhood experience with a drug-addicted father, who is represented as a monstrous but mostly friendly creature, and who becomes blindly aggressive whenever it finds and consumes frogs. While playing as a young boy in the favelas paints a specific picture of Caballero's in-game persona, this representation exhibits slight incongruences with how the designer presents himself (and the game's development company Minority Media) in interviews so that both channels of self-presentation constantly re-ambiguate each other.

\section{Game-making as a technology of the self}

A second, related framework for interpreting autobiographical game-making and the curation on in-game personas is Foucault's notion of 'technologies of the self' or 'care of self', that is, 
technological provisions that afford the "social construction of personal identity" (Aycock 1995). To operationalise that concept, Aycock proposes four distinct elements,

a) an 'inner substance' that constitutes a source or core of personal identity,

b) the 'degree and kind of commitment' with which an activity is carried out,

c) 'personal routines or disciplines' which allow for altering one's identity, and

d) the 'goal of the personal transformation'.

Aycock 'applies' these four elements to identity curation via the early online newsgroup 'rec.games.chess' (RGC), which makes his observations (even if they date back to a very early example of online social interaction) compatible with the case at hand. While the members of the community use the game of chess (and particularly "the purchase and use of chess computers as icons of mastery") to characterise themselves among their peer group, a growing number of autobiographical game-makers use their unpolished, sometimes even unfinished vignettesvi for that same purpose.

A tentative investigation of paratextual elements such as developer statements and user comments in the Interactive Fiction Database ('autobiograph*2017) (which does not yet constitute a stable and active community but does provide an online social context for makers of autobiographical games), allows us to assess the transferability of Foucault's technologies of the self. Self-descriptions on the site indicate that many authors write (and share their works) rather quickly and impulsively, which underlines the performative quality of this practice. Yet, likely because of that perceived 'immediacy' and the formal imperfections, they also consider the 'games-as-texts' to contain some kind of personal truth. For instance, a designer calling herself Snoother argues that her game "is flawed, having been written quickly and intensely" but that "there's something sacrosanct about it for me, and I just can't bring myself to revise it" (Snoother 2015). The term 'sacrosanct' even suggests a connection between the game and the author's body, as it originally refers to the inviolability of a sacred place, object, or person. Thus, the game clearly express part of its creator's inner substance as per Aycock's definition above.

As of February 2017, the IFDB contains 24 autobiographical games, most of which have been reviewed by the community. Surprisingly, most games from that corpus are rated rather negatively and, based on the content of the reviews, it appears that game-makers need to find a precarious balance between being personal but not overbearing in how they position their past experiences and interpretations of them. Indeed, this appears closely reminiscent of Aycock's (1995) observation on the chess community that "an ideal commitment to chess adopts a demeanor which is neither too distant nor too involved".

On the other hand, the definition of an 'inner substance' differs between both communities. Aycock argues that the "romantic idea of 'genius'", that is, players who are able to revolutionise established forms of playing chess by virtue of their overwhelming level of skill, is a prominent trope (or even, one could argue, a consistent persona) by which players essentially define their personal identity, mostly as an ideal type that they strive towards. A corresponding but more intimate trope among autobiographical game-makers and their audience is that of the friend. For instance, a reviewer of Deirdra Kiai's I'm Really Sorry About That Thing I Said When I Was Tired and/or Hungry states that while playing he/she "felt like Kiai's best friend having a conversation with someone I've known my whole life" (Ondricek 2014). In other reviews, a similar sentiment is, more indirectly, expressed through the emotional and empathetic choice of words. For example, a reviewer of the game Ash, which tackles the author's experience with the 
imminent death of his mother, points out how the tone of writing "despite everything, despite everything, remains hopeful" (emphasis in original, verityvirtue 2017).

Finally, to illustrate the relevance of routines for the 'care for self', Aycock investigates how users of RGC routinely refer to habitual practices (e.g. comparing player ratings) or their own personal standards and thresholds (e.g. the best clock setting for 7-year-old children), as well as how to determine them. Arguably, these practices are interpreted as indexical of the persona that the respective users cultivate within the online community. In a similar manner, users on IFDB invoke standards of 'good' autobiographical writing in their comments, thereby also establishing standards as well as routines to uphold them. Some users refer to technological affordances of specific creation tools as part of their personal identity. For instance, one reviewer states: "I never thought CYOA games can be this good. I usually looked down on them, thinking parser commanded games were the best" (BlitzWithGuns 2014). CYOA (Choose-YourOwn-Adventure) refers to the multiple-choice model of tools like Twine while parser-based games (those that accept natural language player input), require more complex tools such as Inform. These interface conventions are discussed as de-facto standards, which are shared or, at least, acknowledged within the community, and by which users can quickly and effectively communicate their respective level of technological sophistication. As many members are both readers and writers, they perform a 'craftsman' persona, characterised by personal identification with tools of the trade, not unlike the identificatory relationship with chess computers in Aycock's case. Other reviewers point out formal elements of writing such as allowing for pauses or implementing "ambiguity about whether you are supposed to click something or not" (Ondricek 2013). This awareness of 'quality standards', as well as criticising games that do not meet them, appears as a recurring pattern by which users perform their own identity as part of the group and, more specifically, justify tackling autobiographical themes (which still constitute only a small sub-section of amateur games) in the first place.

While autobiographical game-making is still far from becoming a widespread social 'movement,' other platforms such as the game distribution service itch.io are gradually emerging to provide a social context for this type of content. The goal of this article has been to outline a theoretical framework to analyse the use of personas in autobiographical games as sets of interrelated procedures and to show how these games as theoretical objects (Bal 2013) become part of their creators' identity politics. A more exploratory approach was chosen that can be used as a foundation for more in-depth close readings in follow-up research. Larger, commercially successful autobiographical games like That Dragon, Cancer and Papo Y Yo have been deliberately left out of this argument but would warrant further attention.

\section{END NOTES}

i For instance, a Wall Street Journal article from June 2016 explains how not only game development but also gaming culture have become multimillion-dollar businesses; see Kelly, M 2016, 'How Gaming Has Become a Multimillion-Dollar Video Business', Wall Street Journal, 16 June, retrieved 5 June 2017, <http://www.wsj.com/video/how-gaming-has-become-amultimillion-dollar-video-business/554DC3AD-C618-4748-AFEBB1B4C10902DE.html>

ii Even Let's Players like Markiplier, who is known for being loud and extrovert in his videos, approach the game very carefully, trying explicitly not to misread or misrepresent it; see https://www.youtube.com/watch?v=5sWTD6vmH_U\&t=0h26m30s. 
iii While the name in the title seems to rule out autobiographical qualities, Deets' blog articles (e.g. http://ayresdeets.com/confidence/) clearly indicate personal connections to the theme of the game. It explores the impact that social anxiety can have on a college student's life by simulating the uneasiness of its protagonist that comes with having to prepare oatmeal in the dorm's public kitchen late in the evening.

iv The term 'bridge' could be further elaborated upon as it could also be argued that the persona constitutes an epistemic 'bridge' between player and author; however, at this point it is used primarily to describe how interacting with the protagonist (often but not necessarily the author persona) is framed by the interface.

v An overview of Yang's games can be found at <https://radiatoryang.itch.io/>

vi For example, the online store itch.io is becoming a hub for playable autobiographical sketches see $<$ https://itch.io/search?q=autobiographical $>$.

\section{WORKS CITED}

'autobiograph' 2017, Interactive Fiction Database, retrieved 5 June 2017, <http://ifdb.tads.org/search?searchbar=autobiograph*\&searchGo.x=0\&searchGo.y=0>

Aycock, A 1995, 'Technologies of the Self: Foucault and Internet Discourse', Journal of ComputerMediated Communication, vol. 1, no.2, retrieved 5 June 2017, <http://doi.wiley.com/10.1111/j.1083-6101.1995.tb00328.x.>

Bal, M 2013, 'Imaging Madness: Inter-ships'. InPrint, vol. 2, no.1, pp.51-70, retrieved 5 June 2017 <http://arrow.dit.ie/inp/vol2/iss1/5>

Barros, CA 1992, 'Figura, Persona, Dynamis: Autobiography and Change', Biography, vol. 15, no.1, pp. 1-28.

BlitzWithGuns 2014, 'A very unique CYOA', IFDB, comment, 21 November, retrieved 5 June 2017, <http://ifdb.tads.org/viewgame?id=fk8xds3a66pyx208>

Bogost, I 2008, 'The Rhetoric of Video Games', in K Salen (ed.) The Ecology of Games: Connecting Youth, Games, and Learning. The MIT Press, Cambridge, MA, pp. 117-140.

-2009, 'Videogames are a Mess', keynote presentation to DiGRA, Uxbridge, UK, 1-4 September, retrieved 5 June 2017, <http://bogost.com/downloads/Videogames are a Mess slides.pdf.>

Camilleri, A 2016, 'Games an Autobiography: Game Design is my Psychologist', presentation to Codemotion, 18-19 March, Rome, retrieved 5 June 2017,

$<$ http://www.slideshare.net/Codemotion/games-and-autobiography-game-design-ismy-psychologist>

Case, N 2014, Coming Out Simulator, Videogame, <https://ncase.itch.io/coming-out-simulator2014>

Cherry, RD 2007, 'Ethos Versus Persona. Self-Representation in Written Discourse', Written Communication, vol. 15, no. 3, pp. 384-410.

Dion, D \& Arnould, E 2016, 'Persona-fied brands: managing branded persons through persona', Journal of Marketing Management, vol. 32, no.1-2, pp. 121-148.

Ellison, C 2013a, 'Anna Anthropy and the Twine revolution', The Guardian, retrived 5 June 2017, <https://www.theguardian.com/technology/gamesblog/2013/apr/10/anna-anthropytwine-revolution>

—2013b, Sacrilege, Videogame, <http://www.unwinnable.com/2013/04/25/play-atheartbreaking-with-cara-ellison/>

Freeman, N 2014a, Space Dad, Videogame, <http://ninasays.so/spacedad/>

—2013b, how do you Do it?, Videogame, <http://store.steampowered.com/ap/353360/> 
Frissen, V, Lammes S, de Lange M, de Mul, J \& Raessens, J 2015, 'Homo ludens 2.0: Play, media, and identity', in Frissen, V, Lammes S, de Lange M, de Mul, J \& Raessens, J (eds.) Playful Identities. The Ludification of Digital Media Cultures, Amsterdam University Press, Amsterdam, pp. 9-52.

Frissen, V, de Mul, J \& Raessens, J 2013, 'Homo ludens 2.0: Play, Media and Identity', in J. Thissen, R. Zwijnenberg, \& K. Zijlmans (eds.), Contemporary Culture. New Directions in Art and Humanities Research, Amsterdam University Press, Amsterdam, pp. 75-92.

Gamespot Staff 2009, 'GDC 2009: Game Design Challenge tackles My First Time', Gamespot, retrieved 5 June 2017, <http://www.gamespot.com/articles/gdc-2009-game-designchallenge-tackles-my-first-time/1100-6206790/>

Goffman, E 1956, The Presentation of Self in Everyday Life, University of Edinburgh Social Sciences Research Centre, Edinburgh.

Haggis, M 2016, 'Creator's discussion of the growing focus on, and potential of, storytelling in video game design', Persona Studies, vol. 2, no. 1, pp. 20-26.

Huizinga, J 1949, Homo Ludens. A study of the play-element in culture, Routledge \& Kegan Paul, London, Boston and Henley.

Idoughi, D, Seffah, A \& Kolski, C 2012, 'Adding user experience into the interactive service design loop: a persona-based approach', Behaviour \& Information Technology, vol. 31, no. 3, pp. 287-303.

Jørgensen, K 2013, Gameworld Interfaces, MIT Press, Cambridge, MA.

Loesberg, J 1981, 'Autobiography as genre, act of consciousness, text', Prose Studies, vol. 4, no. 2, pp. 169-185.

Marshall, PD, Moore, C \& Barbour, K 2015, 'Persona as method: exploring celebrity and the public self through persona studies', Celebrity Studies, vol. 6, no. 3, pp. 288-305.

'Memoir En Code: Reissue' 2017, Steam, retrieved 5 June 2017, $<$ http://store.steampowered.com/app/467940/Memoir_En_Code_Reissue/>

Miller, V 2008, 'New media, networking and phatic culture', Convergence: The International Journal of Research into New Media Technologies, vol. 14, no. 4, pp. 387-400.

Moreno, JL 1987, The Essential Moreno: Writings on Psychodrama, Group Method, and Spontaneity, Springer Publishing Company, New York.

Olshen, BN 1995, 'Subject, Persona, and Self in the Theory of Autobiography', Auto/Biography Studies, vol. 10, no. 1, pp. 5-16.

Olson, GM, Mack, RL \& Duffy, SA 1981, 'Cognitive aspects of genre', Poetics, vol. 10, no. 2-3, pp. 283-315.

Ondricek, H 2013, 'Deeply personal', IFDB, comment, 15 December, retrieved 5 June 2017, <http://ifdb.tads.org/viewgame?id=fk8xds3a66pyx208>

-2014, 'Quality Time With Deifra Kiai!', IFDB, comment, 9 August, retrieved 5 June 2017, < http://ifdb.tads.org/viewgame?id=4j5zyyl3fi99f0sl>

Pelletier, C, Burn, A \& Buckingham, D 2010, 'Game design as textual poaching: Media literacy, creativity and game-making', E-Learning, vol. 7, no. 1, pp. 90-107.

Poremba, C 2007, 'Play with me: Exploring the autobiographical through digital games', in Situated Play, Proceedings of DiGRA 2007 Conference. pp. 703-707, retrieved from <http://www.digra.org/wp-content/uploads/digital-library/07311.15270.pdf.>

Ren'Py 2017, What is Ren'Py?, retrieved 5 June 2017, <https://www.renpy.org>

Rheingold, H 1991, Virtual Reality, Summit Books, New York.

Rohrer, J 2007, What I was trying to do with Passage, retrieved 5 June 2017, <http://hcsoftware.sourceforge.net/passage/statement.html>

- J 2008, A note about Gravitation, retrieved 5 June 2017, $<$ http://hcsoftware.sourceforge.net/gravitation/statement.html>.

Rössler, P 2012, 'Comparative content analysis', in F. Esser \& T. Hanitzsch (eds.), Handbook of Comparative Communication Research, Routledge, New York, pp. 459-468.

Roth, ME 2015, 'At the Edge of a "Digital Area" - Locating Small-Scale Game Creation', Asiascape: Digital Asia, vol. 2, pp. 183-212. 
Schleser, M 2014, 'Connecting through mobile autobiographies: Self-reflexive mobile filmmaking, self-representation, and selfies', in M. Berry \& M. Schleser (eds.), Mobile Media Making in an Age of Smartphones. Palgrave Macmillan, New York, pp. 148-158.

Shankar, A 2000, 'Lost in music? Subjective personal introspection and popular music consumption', Qualitative Market Research: An International Journal, vol. 3, no. 1, pp. 2737.

Smith, E 2015, “'Actual Sunlight” Might Be the Most Painfully Real Video Game You'll Ever Play', Vice, retrieved 5 June 2017, <https://www.vice.com/en_us/article/actual-sunlightmight-be-the-most-painfully-real-video-game-youll-ever-play-000>

Snoother 2015, 'Sleep', Interactive Fiction Database, page version 6, 8 April, retrieved 5 June 2017, <http://ifdb.tads.org/viewgame?version=6\&id=oaewsdd7ugqkre5v>

St. John, B 2014. 'Conveying the sense-making corporate persona: The Mobil Oil "Observations" columns, 1975-1980', Public Relations Review, vol. 40, no. 4, pp. 692-699.

Stern, BB 1993, "The Firm, the Author, and the Persona: A Literary Model of the Source of Advertising', Journal of Current Issues \& Research in Advertising, vol. 15, no. 2, pp. 15-24.

The Average Everyday Adventure of Samantha Brown - Birdie Sanders - PART 1 2016, YouTube, Commander Holly, 9 April, retrieved 5 June 2017, $<$ https://www.youtube.com/watch?v=s1aoQMFdW_w>

Thompson, C 2002, 'Dot-Columnist. Online video games are the newest form of social comment', Slate, retrieved 5 June 2017, <http://www.slate.com/articles/technology/webhead/2002/08/dotcolumnist.html>

Treanor, M \& Mateas, M 2011, 'BurgerTime: A Proceduralist Investigation', in Proceedings of DiGRA 2011 Conference: Think Design Play. Utrecht, retrieved from $<$ http://www.digra.org/digital-library/publications/burgertime-a-proceduralistinvestigation/>

Tronstad, R 2015, 'Presence and mediation: on the participatory SMS performance Surrender Control (2001, Tim Etchells)', International Journal of Performance Arts and Digital Media, vol. 11, no. 1, pp. 54-64.

Twine 2017, Twine is an open-source tool for telling interactive, nonlinear stories, retrieved 5 June 2017, <https://twinery.org>

Verityvirtue 2017, 'A midlength Meditation on a parent's dying', IFDB, comment, 8 January, retrieved 5 June 2017, < http://ifdb.tads.org/viewgame?id=fk8xds3a66pyx208>

Virtanen, T \& Halmari, H 2005, 'Persuasion across genres: Emerging Perspectives', in T. Virtanen \& H. Halmari (eds.), Persuasion Across Genres: A Linguistic Approach, John Benjamins, Amsterdam \& Philadelphia, pp. 3-26.

Wallin, MR 2007, 'Myths, Monsters and Markets: Ethos, Identification, and the Video Game Adaptations of The Lord of the Rings', Game Studies, vol. 7, no. 1, retrieved 5 June 2017, <http://gamestudies.org/0701/articles/wallin>.

Werning, S 2017 'Analytical Game Design. Game-making as a cultural technique in a gamified society', in R. Glas, S. Lammes, M. de Lange, J. Raessens \& I. de Vries (eds.), The Playful Citizen: Knowledge, Creativity, Power, Amsterdam University Press, Amsterdam (in print).

White, N 2016, 'Gaming to cope: how developers are tackling real life', The Telegraph, retrieved 5 June 2017, <http://www.telegraph.co.uk/gaming/what-to-play/personal-issuesinside-the-fascinating-world-of-interactive-biog/> 